OPEN ACCESS

Edited by:

Traci Giuliano,

Southwestern University,

United States

Reviewed by:

Stuart McKelvie,

Bishop's University, Canada

Tonya Bergeson-Dana,

Butler University, United States

*Correspondence:

Lynne D. Roberts

lynne.roberts@curtin.edu.au

Specialty section:

This article was submitted to

Educational Psychology,

a section of the journal

Frontiers in Education

Received: 13 September 2018 Accepted: 23 November 2018 Published: 04 December 2018

Citation:

Roberts LD and Seaman K (2018)

Students' Experiences of

Undergraduate Dissertation

Supervision. Front. Educ. 3:109

doi: 10.3389/feduc.2018.00109

\section{Students' Experiences of Undergraduate Dissertation Supervision}

\author{
Lynne D. Roberts * and Kristen Seaman \\ School of Psychology, Curtin University, Perth, WA, Australia
}

Increasingly, students completing undergraduate dissertations in Australia are expected by their supervisors to produce publishable research. Despite this, limited resources are available for supervisors of undergraduate dissertation students on how best to supervise students toward this aim. Building on our previous research on the perspectives of supervisors and dissertation coordinators of what constitutes good undergraduate dissertation supervision, we present here the findings on student perspectives of good supervision. Twenty-five students (seventeen students who were currently completing an undergraduate dissertation and eight who had recently completed an undergraduate dissertation) were interviewed about their experiences in being supervised. A critical incident methodology was used to invite students to reflect on times when supervision had gone well, and times when it had not. Interviews were recorded and transcribed and analyzed using thematic analysis. Key themes to emerge were that students viewed "good" supervisors as those that were supportive and empowering, directed learning, and whose style and interests aligned with those of the students. Challenges in supervision related to lack of clarity and inconsistencies, perceived power imbalances between students and supervisors, and perceived inequities in the amount of supervision provided across students. Whilst the publication of undergraduate research is a worthy aim, the pressure to publish for some students resulted in feelings of inadequacy and perceptions of supervisors losing interest when findings were not deemed publishable.

Keywords: undergraduates, dissertations, student perceptions, supervision, undergraduate research

\section{INTRODUCTION}

Undergraduate dissertations are capstone experiences that provide students with an opportunity to answer a research question within a disciplinary framework under supervision (Ashwin et al., 2017). They form an essential component of many undergraduate degrees, provide a transition between course work and independent research, and may result in publishable research. Publication of findings can benefit both student and supervisor in the "publish or perish" culture of neoliberal universities (Besley and Peters, 2009) which function on a market-driven corporate governance model (Enright et al., 2017). However, this drive to publish also potentially positions students as research assistants completing research tasks proscribed by the supervisor to further their own research rather than learners developing independence in designing and conducting research (Kiley et al., 2011). Despite these tensions, limited research has examined supervisory practices or the experiences of undergraduate dissertation students. The plethora of research on doctoral students 
(see Bastalich, 2017 for a review) cannot be readily applied to undergraduate dissertation students as undergraduate students have no or limited previous independent research experience (Cook, 1980), may have lower interest in conducting research (Cook, 1980) and need to complete their research in a shorter timeframe (Rowley and Slack, 2004).

Research conducted with supervisors of undergraduate dissertation students indicates that supervisors perceive they contribute to good supervision through providing directed and clear advice, supporting and instilling confidence in students and fostering student independence and growth (Roberts and Seaman, 2018). However, in this and previous studies examining supervisors' perspectives (e.g., Todd et al., 2006; Wiggins et al., 2016), the paucity of training and resource materials available for supervisors of dissertations at this level has been noted.

Previous research with students indicates that while they valued the increased autonomy, support of supervisors, and authenticity of completing an undergraduate dissertation, they faced uncertainty and challenges in collecting data and managing time (Todd et al., 2004). A recent quantitative exploration of students' experiences of undergraduate dissertation supervision (Vera and Briones, 2015) suggests that upwards of a third of students may not be satisfied with the supervision they receive. In the research presented here we further explore students' perceptions of undergraduate dissertation supervision.

The current research is situated in a large university that is repositioning as a research-intensive university within the Australian higher education sector, where government financial assistance to universities increases with research output (Heffernan, 2017). Reflecting the increasing emphasis on research outputs, the format of honors dissertations in some disciplines has changed from a traditional dissertation to a journal article format ${ }^{1}$, a strategy intended to increase the number of publications resulting from honors research projects.

\section{METHODS}

\section{Participants}

Twenty-five students from health science disciplines (including psychology and speech pathology) within one Australian university were interviewed for this research. At the time of the interview, 17 students were currently completing an undergraduate dissertation and eight had recently completed an undergraduate dissertation (five within the last year; not all within the same university) and were now enrolled in a masters or PhD program. Seventeen students discussed their experiences in undertaking an honors dissertation (ten current and 6 completed), while 8 students discussed completing an undergraduate dissertation in the pass stream (non-honors) of a program (7 current and 1 completed). The majority of students (56\%) were aged between 20 and 29 years, and all but three of the honors students were female.

\footnotetext{
${ }^{1}$ For example, the Australian psychology guidelines for undergraduate dissertations currently permit either a traditional dissertation or a journal article format (Australian Psychology Accreditation Standards for Psychology Courses, 2010).
}

Students experienced a range of supervisory arrangements. Honors students received individual supervision (although for some this occurred in a group setting) while pass stream students worked together in groups and received group supervision. Six of the female students had one female supervisor, five had one male supervisor, and ten had two supervisors (six had two female supervisors, 1 had two male supervisor and three had one female and one male supervisor). One male student had a female supervisor and two had male supervisors. Supervision arrangements changed for some students over time with supervisors leaving or being added, or in one case being replaced altogether.

\section{Measures}

A semi-structured interview guide was developed based on critical incident methodology (Flanagan, 1954; Butterfield et al., 2005). Preliminary questions asked the student to describe their dissertation project, the supervisory arrangements for their project and their relationship with their supervisors. Critical incident methodology questions asked students to identify and describe times when from their perspective supervision had gone well, and not so well. Prompts invited students to reflect on contributing factors to these situations. The final question invited students to make any further comments about their supervisory experiences.

\section{Procedure}

This research was approved by Curtin University Human Research Ethics Committee (Approval No. PSYCH SP 2013-13). Interviews were conducted by the first author, audio-recorded, transcribed and entered into NVivo (v.10), a qualitative data analysis computer software package, for analysis. An inductive thematic analysis was conducted, following the procedures outlined by Braun and Clarke (2006). Both authors read all transcripts as part of the familiarization phase. The first author conducted a preliminary analysis. As a form of respondent validation, a summary of findings from the preliminary analysis was returned to participating students and comments invited. This was followed by the second author coding all transcripts independently and developing themes. Good concordance was found between themes developed in the two analyses.

\section{RESULTS}

From students' discussions of good supervisory practice, three key themes emerged: supportive supervisory relationships, directing learning to empower students, and an alignment of student-supervisor interests and approaches. Each of these themes, along with definitions and example quotes is presented in Table 1. While each of these themes places the emphasis on the role of the supervisor, students acknowledged that good supervisory experiences also required effort on their part. Good supervision was enabled by students taking ownership of the research project and preparing for supervisory meetings. Where 
TABLE 1 | Themes underlying students' perceptions of good supervision.

\begin{tabular}{ll}
\hline Theme & Definition \\
\hline $\begin{array}{l}\text { Supportive supervisory } \\
\text { relationships }\end{array}$ & $\begin{array}{l}\text { Good supervisors were perceived by students } \\
\text { as approachable, available and a person they } \\
\text { may turn to for emotional support }\end{array}$
\end{tabular}

"I always feel like I can go to her for help and I never feel like I'm a burden." "She takes interest in my life outside of uni, so she's like, 'How are you going?' And whatever, and she's always like, "If you have any other problems?" I don't know. I know that if anything comes up, that door is open, that I can communicate with her about that stuff."

"She's always replying to e-mails at a drop of a hat."

"...knowing that you can access a bit of emotional support as well, not therapy, but just having that understanding and someone who's sort of compassionate and flexible and understanding."

"I've always felt like she's made more than enough time for me to have my questions answered or to have the support from her and stuff."

Directing learning to empower students
Moving from explicit directions at the beginning to challenging students' thinking as they progress instills confidence and empowers students to become competent, independent researchers
Student-supervisor alignment
Compatibility of interests and preferred approaches to supervision
"You have this ideology of what supervision should be, okay, and when you think about what it is and who the people who are involved, you envisage a mentor. We are students; we need to be shown"

"So really clear good direction and time really well spent because it's directing us exactly where we need to go"

"I would bring it to him and then he would say, "No, that's good but perhaps you should also think about this because this might also be impacting. So go back, have a read into that and then come back and then we'll discuss."

"I do feel like a sheep. Not like a sheep, but I'm like this new fresh lamb and these are my shepherds. <laughs> They're helping me along like, 'Here's the best grass over here.' Without telling me what to do."

"..she's really good at guiding the research and if we're ever at a loss, she'll be able to fill in the gaps but she would do it in a way which we do it ourselves. She just facilitates it."

"He was initially like, I guess, sort of a repository of experiential knowledge and information and that. But he soon became a bit more of a mentor or a coach, and I felt he would kind of facilitate my own learning rather than tell me what to do. Toward the end, ... it took on, say, more of a supportive role. I felt like my supervisor knew I was capable of completing the dissertation and was just there to sort of allay any concerns I had, those sorts of things."

"And I think a good balance between giving suggestions without taking over and saying, "Just do this." So just giving enough sort of food for thought and feedback so that I felt like I still had some sort of input into the changes and the corrections and whatever, but it wasn't just totally sort of placed on me."

"She's so passionate about this area and so that makes it interesting and sort of fun to work alongside her in"

"I think she has a better idea of who I am, therefore she knows how far she can throw me in the deep end."

"When I first approached one of the supervisors last year she was like, 'I'm not going to hold your hand and if that's what you wanted in a supervisor then we won't work well together.' And I went, 'No that's exactly what I want.' Like I'm a person that works fairly independently."

"I'm relatively independent and I just like being able to touch base for important things and just to check in that things are going okay and like, my supervisor now knows that that's sort of how I work and probably has learned to trust that." supervision meetings went well, students reported feeling remotivated, with increased focus and clarity about the project.

Whilst most students reported positive supervisory experiences, some experienced difficulties in the relationship. From students' discussions of times when supervision did not go well, five themes emerged: lack of clarity, inconsistencies, power imbalances, inequities and overworked supervisors who are under pressure to publish. Each of these themes, along with definitions and example quotes is presented in Table 2. Underlying these themes are differences in expectations between students and supervisors.

The key differences emerging between honors and pass stream students related to the group composition. Honors students choose their own supervisor(s) and topics (at least to some degree) while pass stream students were assigned to groups and had limited choice of supervisor or topic. Overall, pass stream students expressed less passion about their topics (at least in the early stages) and sometimes experienced conflict with other group members (e.g., social loafing, dominant group members).

\section{DISCUSSION}

This research aimed to explore students' conception of good supervision of undergraduate dissertations. Encouragingly, all but one student were able to highlight a time when supervision had gone well, with students able to identify both the supervisors 
TABLE 2 | Themes relating to students' perceptions of supervisory challenges.

\begin{tabular}{|c|c|c|}
\hline Theme & Definition & Example quotes \\
\hline Lack of clarity & $\begin{array}{l}\text { Lack of specific guidance on how to progress } \\
\text { with research projects impacting on speed of } \\
\text { progress }\end{array}$ & $\begin{array}{l}\text { "It's challenging because sometimes he's not directive in what he's saying. He's, "Well } \\
\text { you could do this," and "You could do this," and "You could do this," and "You could } \\
\text { do this"." } \\
\text { "They're [supervisors] still not a } 100 \text { percent and sometimes it takes chunks of time, } \\
\text { them going back to somebody else and then relaying the information back. So in total } \\
\text { it's put us back about } 2 \text { or } 3 \text { weeks." } \\
\text { "The only problem that l've been having is that with my analysis, it's been completely } \\
\text { mucked up. And that was on the level that my supervisors were confused by my } \\
\text { analysis, which means that I have only just run the correct analysis just now." }\end{array}$ \\
\hline Inconsistencies & $\begin{array}{l}\text { Inconsistencies in advice given by supervisors, } \\
\text { and between supervisors and marking guides }\end{array}$ & $\begin{array}{l}\text { "It's harder being two supervisors that think differently and give conflicting advice." } \\
\text { "On occasion I would get sometimes different feedback on like the same sort of I } \\
\text { guess draft." } \\
\text { "My supervisor said that, "yeah, those guidelines are just-if you want to get good } \\
\text { marks and stuff but I, personally, think you don't have to do all those things." } \\
\text { "I wanted to satisfy the requirements of the dissertation and do the by-the-book } \\
\text { approach, but I didn't wanna offend my supervisor. I didn't wanna put his nose out of } \\
\text { joint." } \\
\text { "The supervisor is perhaps not being familiar with the requirements for honors or not } \\
\text { perceiving them as very important to themselves." }\end{array}$ \\
\hline Power imbalances & $\begin{array}{l}\text { Perceived power imbalance between students } \\
\text { and supervisors results in students feeling } \\
\text { powerless to voice concerns }\end{array}$ & $\begin{array}{l}\text { "I think there's this power differential. You know, it's an "us" and "them." And as a } \\
\text { student I've always felt it." } \\
\text { "But then I didn't have the courage to say to them, "Hang on a minute. This is not } \\
\text { right." So instead I would just stay quiet and mumble and grumble." } \\
\text { "... one of my supervisors is hopefully my supervisor for a PhD. So I really felt like I } \\
\text { couldn't alienate myself in any way and being like, 'You guys are wrong. You kind of } \\
\text { let me down.' And then have the potential for that to backfire on me in the future." } \\
\text { "But the times that I have plucked up the courage to say something they've got } \\
\text { defensive at me. So then I retreat back again and then I'm fearing well if I take it any } \\
\text { further then what do I do about my future prospects?" }\end{array}$ \\
\hline Inequities & $\begin{array}{l}\text { Students' perceptions that the amount and } \\
\text { quality of supervision provided varies greatly }\end{array}$ & $\begin{array}{l}\text { "...some students may get an hour, one student may only get half an hour, some will } \\
\text { get their results read three times, some will only get it once. There's a lot of } \\
\text { differences" } \\
\text { "There's a little group that we share the same [supervisors], and my goodness their } \\
\text { supervision is fabulous and they'll have a different perspective. But we see what they } \\
\text { get, it's actually really soul destroying." } \\
\text { "On a more personal note, some of my colleagues and people that I know have not } \\
\text { had the same type of treatment or support and that's caused a lot of conflict for me } \\
\text { personally." }\end{array}$ \\
\hline $\begin{array}{l}\text { Overworked supervisors } \\
\text { who are under pressure to } \\
\text { publish }\end{array}$ & $\begin{array}{l}\text { Students perceptions that supervisors are } \\
\text { overworked and under pressure to publish, } \\
\text { negatively impacting on the supervisory } \\
\text { experience }\end{array}$ & $\begin{array}{l}\text { "I think they've got too many students. And they're forgetting, I think that's what is } \\
\text { happening. They're overloaded, big time. And they're overworked.." } \\
\text { "They're too tired, you see it, and they're exhausted. They keep saying, I'm tired, I'm } \\
\text { tired. I hear you, I see it, you can actually see how exhausted you are, you know, and } \\
\text { yeah." } \\
\text { "I think that there's been added pressure with supervisors having to publish more, we } \\
\text { feel it, it's all about publish, publish, publish. I found non-significant results and I felt } \\
\text { inadequate almost" } \\
\text { "Fishing is soul-destroying, and you don't even know what you're looking for } \\
\text { anymore, and changing of hypotheses." } \\
\text { "I think as well the pressure of publications because I didn't find anything, they seem } \\
\text { to lose a little bit of interest." }\end{array}$ \\
\hline
\end{tabular}

and their own contribution to positive experiences. In accordance with previous research in this area (Todd et al., 2004) students valued the support of supervisors and their increasing autonomy.

Most students were also able to describe a time when supervision had not gone so well, and these experiences were characterized by differences in expectations between students and supervisors. Consistent with Todd's (2004) finding of students experiencing uncertainty, lack of clarity and inconsistences were key themes to emerge in this research. However, unlike Vera and Briones (2015) finding of upwards of a third of students not being satisfied with their students, a more nuanced picture emerged in this study with students able to identify both times when supervision was going well, and times when it did not.

Of concern, the findings indicate that the pressure to publish experienced by academics within a neoliberal university setting is in some cases being transmitted to students and has the potential to impact upon supervisory experiences for undergraduate students. While only a minority of students 
interviewed referred to this tension, the findings highlight the need for supervisors to not let their own disappointment translate into poorer supervision when students' research is not publishable. One participant reported "fishing" for significant results, aligning with recent research reporting that supervisors shape students' attitudes toward questionable research practices (Krishna and Peter, 2018). Student engagement in questionable research practices has also been documented earlier in the undergraduate degree (Rajah-Kanagasabai and Roberts, 2015), further highlighting the need for supervisors to clearly articulate best practices and demonstrate these in their own research. The primary purpose of the undergraduate dissertation is the research learning experience for the student, and potential publication needs to be viewed as a bonus rather than an expectation. Whilst publication in high impact peer-reviewed journals may be a priority for supervisors, students can also benefit from other avenues of dissemination, such as presenting findings at conferences or publishing in student research journals.

This research was conducted within one university that is repositioning as a research-intensive university. Supervisory practices may vary across universities according to the focus of the university (teaching vs. research) and the resources provided, and may also vary across disciplines. Given the range of supervisory arrangements (single vs. multiple supervisors, single vs. multiple students) and gender mixes within these arrangements, it was not possible to tease out potential differences in perceptions of supervision according to gender concordance/discordance between supervisors and students. This is an area that warrants further research.

Despite these limitations, the findings provide insight into what students' value and find challenging in their undergraduate dissertation supervisory relationships, and may have some transferability across different academic settings. The findings from this research, along with interviews with new supervisors

\section{REFERENCES}

Ashwin, P., Abbas, A., and McLean, M. (2017). How does completing a dissertation transform undergraduate students' understandings of disciplinary knowledge? Assess. Eval. High. Educ. 42, 517-530. doi: 10.1080/02602938.2016. 1154501

Australian Psychology Accreditation Standards for Psychology Courses (2010). Rules for Accreditation and Accreditation Standards for Psychology Courses. Available online at: https://www.psychologycouncil.org.au/sites/default/ files/public/Standards_Rules_2010_Jun_APAC_Accreditation_for\%20_ Psychology_Courses_v10.pdf

Bastalich, W. (2017). Content and context in knowledge production: a critical review of doctoral supervision literature. Stud. High. Educ. 42, 1145-1157. doi: 10.1080/03075079.2015.1079702

Besley, T., and Peters, M. A. (2009). "Neoliberalism, performance and the assessment of educational research quality: comparing United Kingdom, Australia and New Zealand," in Assessing the Quality in Higher Education: International Perspectives, ed T. Besley (Rotterdam: Sense Publishers), 27-48.

Braun, V., and Clarke, V. (2006). Using thematic analysis in psychology. Qual. Res. Psychol. 3, 77-101. doi: 10.1191/1478088706qp063oa

Butterfield, L. D., Borgen, W. A., Amundson, N. E., and Maglio, A. S. T. (2005). Fifty years of the critical incident technique: 1954-2004 and beyond. Qual. Res. 5, 475-497. doi: 10.1177/14687941050 56924 and workshops with experienced supervisors (see Roberts and Seaman, 2018) informed the development of a range of supervisory resources. A guide for supervisors and a range of supervisory tools for use by supervisors are feely available from http://www.dissertationsupervision.org/, and provide advice on some of the issues raised here, such as the studentsupervisor relationship, co-supervision and managing your supervisory workload. A guide for students is also freely available from https://www.researchgate.net/publication/286239145_ Guide_for_Honors_and_Coursework_Dissertation_Students/ download. This guide covers preparing for supervision, forms of supervision and getting the most from supervision, along with advice for specific stages of the project from the first supervision meeting through to data collection, analysis and interpretation, with a section on overcoming difficulties in managing a research project. We encourage readers to access and use these materials.

\section{DATA AVAILABILITY STATEMENT}

The raw data supporting the conclusions of this manuscript will be made available by the authors, without undue reservation, to any qualified researcher.

\section{AUTHOR CONTRIBUTIONS}

LR was responsible for designing the research, conducting the interviews, reviewing the analysis, and leading the writing of the paper. KS analyzed the interview data.

\section{FUNDING}

This research was funded by the Australian Government Office for Learning and Teaching [OLT 2013 National Teaching Fellowship] awarded to LR.
Cook, M. C. F. (1980). The role of academic supervisor for undergraduate dissertations in science and science-related subjects. Stud. High. Educ. 5, 173-185. doi: 10.1080/03075078012331377206

Enright, E., Alfrey, L., and Rynne, S. B. (2017). Being and becoming an academic in the neoliberal university: a necessary conversation. Sport Educ. Soc. 22, 1-4. doi: 10.1080/13573322.2016.1259999

Flanagan, J. C. (1954). The critical incident technique. Psychol. Bull. 51, 327-358. doi: $10.1037 / \mathrm{h} 0061470$

Heffernan, T. A. (2017). A fair slice of the pie? Problematising the dispersal of government funds to Australian universities. J. High. Educ. Policy Manage. 39, 658-673. doi: 10.1080/1360080X.2017.1377965

Kiley, M., Boud, D., Manathunga, C., and Cantwell, R. (2011). Honouring the incomparable: honours in Australian universities. High. Educ. 62, 619-633. doi: 10.1007/s10734-011-9409-z

Krishna, A., and Peter, S. M. (2018). Questionable research practices in student final theses-Prevalence, attitudes, and the role of the supervisor's perceived attitudes. PLoS ONE 13:e0203470. doi: 10.1371/journal.pone.0203470

Rajah-Kanagasabai, C. J., and Roberts, L. D. (2015). Predicting self-reported research misconduct and questionable research practices in university students using an augmented theory of planned behavior. Front. Psychol. 6:535. doi: 10.3389/fpsyg.2015.00535

Roberts, L. D., and Seaman, K. (2018). Good undergraduate supervision: perspectives of supervisors and dissertation coordinators. Int. J. Acad. Dev. 23, 28-40. doi: 10.1080/1360144X.2017.1412971 
Rowley, J., and Slack, F. (2004). What is the future for undergraduate dissertations? Educ. Train. 46, 176-181. doi: 10.1108/00400910410543964

Todd, M., Bannister, P., and Clegg, S. (2004). Independent inquiry and the undergraduate dissertation: perceptions and experiences of final-year social science students. Assess. Eval. High. Educ. 29, 335-355. doi: 10.1080/02602930420001 88285

Todd, M. J., Smith, K., and Bannister, P. (2006). Supervising a social science undergraduate dissertation: staff experiences and perceptions. Teach. High. Educ. 11, 161-173. doi: 10.1080/135625105005 27693

Vera, J., and Briones, E. (2015). Students' perspectives on the processes of supervision and assessment of undergraduate dissertations. Cult. Educ. 27, 726-765. doi: 10.1080/11356405.2015.10 89391
Wiggins, S., Gordon-Finlayson, A., Becker, S., and Sullivan, C. (2016). Qualitative undergraduate project supervision in psychology: current practices and support needs of supervisors across North East England and Scotland. Qual. Res. Psychol. 13, 1-19. doi: 10.1080/14780887.2015.1075641

Conflict of Interest Statement: The authors declare that the research was conducted in the absence of any commercial or financial relationships that could be construed as a potential conflict of interest.

Copyright $\odot 2018$ Roberts and Seaman. This is an open-access article distributed under the terms of the Creative Commons Attribution License (CC BY). The use, distribution or reproduction in other forums is permitted, provided the original author(s) and the copyright owner(s) are credited and that the original publication in this journal is cited, in accordance with accepted academic practice. No use, distribution or reproduction is permitted which does not comply with these terms. 